\title{
FosB Null Mutant Mice Show Enhanced Methamphetamine Neurotoxicity: Potential Involvement of FosB in Intracellular Feedback Signaling and Astroglial Function
}

\author{
Kumi O Kuroda ${ }^{*, 1}$, Veravej G Ornthanalai ${ }^{2}$, Tadafumi Kato ${ }^{3}$ and Niall P Murphy ${ }^{2,4}$ \\ 'Unit for Affiliative Social Behavior, RIKEN Brain Science Institute, Saitama, Japan; ${ }^{2}$ Neuropathology Research Group, RIKEN Brain Science \\ Institute, Saitama, Japan; '3aboratory for Molecular Dynamics of Mental Disorder, RIKEN Brain Science Institute, Saitama, Japan
}

\begin{abstract}
Previous studies show that ( 1 ) two members of fos family transcription factors, c-Fos and FosB, are induced in frontal brain regions by methamphetamine; (2) null mutation of c-Fos exacerbates methamphetamine-induced neurotoxicity; and (3) null mutation of FosB enhances behavioral responses to cocaine. Here we sought a role of FosB in responses to methamphetamine by studying FosB null mutant (-/-) mice. After a $10 \mathrm{mg} / \mathrm{kg}$ methamphetamine injection, FosB(-/-) mice were more prone to self-injury. Concomitantly, the intracellular feedback regulators of Sprouty and Rad-Gem-Kir (RGK) family transcripts had lower expression profiles in the frontoparietal cortex and striatum of the FosB $(-/-)$ mice. Three days after administration of four $10 \mathrm{mg} / \mathrm{kg}$ methamphetamine injections, the frontoparietal cortex and striatum of $\operatorname{Fos} B(-/-)$ mice contained more degenerated neurons as determined by Fluoro-Jade B staining. The abundance of the small neutral amino acids, serine, alanine, and glycine, was lower and/or was poorly induced after methamphetamine administration in the frontoparietal cortex and striatum of Fos $B(-/-)$ mice. In addition, methamphetamine-treated Fos $B(-/-)$ frontoparietal and piriform cortices showed more extravasation of immunoglobulin, which is indicative of blood-brain barrier dysfunction. Methamphetamine-induced hyperthermia, brain dopamine content, and loss of tyrosine hydroxylase immunoreactivity in the striatum, however, were not different between genotypes. These data indicate that FosB is involved in thermoregulation-independent protective functions against methamphetamine neurotoxicity in postsynaptic neurons. Our findings suggest two possible mechanisms of FosB-mediated neuroprotection: one is induction of negative feedback regulation within postsynaptic neurons through Sprouty and RGK. Another is supporting astroglial function such as maintenance of the blood-brain barrier, and metabolism of serine and glycine, which are important glial modulators of nerve cells.

Neuropsychopharmacology (2010) 35, 64I-655; doi:I0.1038/npp.2009. 169; published online 4 November 2009
\end{abstract}

Keywords: FosB; methamphetamine; neurotoxicity; astroglia; sprouty; Rad-Gem-Kir (RGK) family

\section{INTRODUCTION}

Amphetamines, substituted amphetamines (such as methamphetamine (METH), and 3,4-methylenedioxymethamphetamine (MDMA or 'ecstasy')) and cocaine are widely abused psychostimulants (Sulzer et al, 2005). Whereas cocaine blocks the activity of dopamine, norepinephrine, and serotonin transporters, most amphetamine derivatives promote the release of these biogenic amines by reverse transport, effectively discharging enormous amounts of

\footnotetext{
*Correspondence: Dr KO Kuroda, Unit for Affiliative Social Behavior, RIKEN Brain Science Institute, 2-I Hirosawa, Wako-shi, Saitama 35 I0198, Japan, Tel: +8I 48467 7556, Fax: + 81484676853 ,

E-mail: asbcontact@brain.riken.jp

${ }^{4}$ Current address: Department of Psychiatry and Biobehavioral Sciences, Semel Institute for Neuroscience and Human Behavior, University of California at Los Angeles, Los Angeles, CA, USA.

Received 12 March 2009; revised 17 August 2009; accepted 3 September 2009
}

biogenic amines into the extracellular space. Regardless of the mechanism, a major outcome is a strong potentiation of biogenic amine signaling, and it is this effect that is widely believed to underlie the abuse potential of these drugs. Repeated administration of lower doses or a single highdose administration of amphetamines may lead to depletion of dopamine and serotonin by causing degeneration of neuronal terminals (Krasnova and Cadet, 2009). Such terminal degeneration is not only long-lasting but also recoverable in rodents, as these monoaminergic neurons themselves are resistant (Bowyer and Schmued, 2006b). In contrast, amphetamines can elicit death of neurons postsynaptic to these monoaminergic terminals in many forebrain regions such as the striatum and the frontal and somatosensory cortices (Krasnova and Cadet, 2009). Two forms of cell death have been implicated in this process (Davidson et al, 2001; Gold et al, 2009). One is apoptotic cell death, also referred to as programmed cell death, which is characterized by cell shrinkage, specific DNA fragmentation 
at about $180 \mathrm{bp}$ intervals, and activation of cysteine proteases called caspases. The other form of cell death, necrosis, is a very rapid process, associated with cell swelling, spillage of intracellular substances into surrounding tissue, and nonspecific DNA damage.

Multiple events, including oxidative stress, excitotoxicity (toxicity caused by glutamate release), hyperthermia, mitochondrial and endoplasmic reticulum stress, and the blood-brain barrier (BBB) dysfunction, are implicated in amphetamine-induced neurotoxic effects (Krasnova and Cadet, 2009). These events appear to be intimately related. For example, preventing hyperthermia by cooling the ambient temperature to $4^{\circ} \mathrm{C}$ can decrease molecular markers of oxidative stress, attenuate dopaminergic and serotonergic terminal depletion, and decrease neuronal death in the parietal cortex (Bowyer, 1995; Eisch et al, 1998). Similarly, the glutamate receptor antagonist MK-801 can attenuate hyperthermia, dopaminergic and serotonergic terminal degeneration, and neuronal death in the parietal cortex (Eisch et al, 1998; Tata and Yamamoto, 2007). As such, it is still unclear which mechanism is the most upstream and/or responsible for each neurotoxic end point. Interestingly, however, a dopamine transport inhibitor administered before METH can only prevent striatal tyrosine hydroxylase immunoreactivity loss, but not hyperthermia or neuronal death in the parietal cortex (Eisch et al, 1998). In addition, it has been shown that the striatal subregion that contains the greatest number of degenerated neurons is different from the subregion showing greatest loss of tyrosine hydroxylase immunoreactivity (Bowyer et al, 2008). It is therefore likely that mechanisms of striatal dopamine terminal damage exist independent of the mechanisms responsible for postsynaptic cell injury and hyperthermia.

Amphetamines stimulate the expression of many immediate early genes, particularly those of the Fos family transcription factors, which include c-Fos, FosB, Fra-1, and Fra-2 (Herdegen and Leah, 1998). $\Delta$ FosB, a truncated splice variant of FosB, is induced in the striatum by chronic exposure to abused drugs (Nestler, 2001). The persistent expression of $\Delta$ FosB has been implicated in long-term adaptations that underlie patterns of behavior characteristic of addiction. Previous studies have also shown that FosB null mutant $(-/-)$ mice show exaggerated locomotor activation following initial cocaine exposure and robust conditioned place preference to a lower dose of cocaine (Hiroi et al, 1998). In addition, c-Fos(-/-) and (+/-) mice show exacerbated METH-induced neurotoxicity as reflected in a greater loss of striatal tyrosine hydroxylase-like immunoreactivity and dopamine-reuptake sites and more neuronal apoptosis in their cortices and striata. These results suggest that Fos family proteins may be involved in the protective mechanisms against METH-induced neurotoxicity.

Being important elements of transcriptional regulation of cellular functions, c-Fos and FosB are also likely to be involved in the regulation of many behaviors. An example is parental behavior, which arises from neuronal activity in the medial preoptic area of the hypothalamus (Brown et al, 1996; Numan et al, 1998). As to this, FosB(-I-) mice show abnormal parenting (Brown et al, 1996). Our previous studies suggest that the role of Fos $B$ in this behavior is to induce in downstream target genes such as Sprouty1 (SPRY1) and RAD, under the control of extracellular signal-regulated kinase (ERK) (Kuroda et al, 2007). The Sprouty family consists of three members in mouse, SPRY1, SPRY2 and SPRY4, and represents a major class of ligandinducible inhibitors of the receptor tyrosine kinase (RTK)dependent ERK signaling pathway (Mason et al, 2006). RAD is a member of the Rad-Gem-Kir (RGK) family small GTPbinding proteins that encompasses RAD, GEM/KIR, REM and REM2, which function as potent inhibitors of voltagedependent calcium channels (Kelly, 2005). The ERK-FosBSPRY1/RAD signaling therefore appears to provide critical feedback regulation of neuronal adaptation in the initiation of parental care (Kuroda et al, 2007). It seems likely that this intracellular signaling cascade is also involved in other behaviors, such as those in response to METH and other psychostimulants. For instance, $c$-Fos heterozygous mutant $(+/-)$ mice, in which METH-induced dopaminergic terminal damage and neuronal apoptosis are exacerbated (Deng et al, 1999), show significant impairment in GEM (a member of RGK family) upregulation in the striatum compared with wild-type mice on METH administration (Cadet et al, 2002). Administration of MDMA causes ERK activation and subsequent upregulation of REM2, another member of RGK, along with $c$-Fos and FosB in the striatum (Salzmann et al, 2006). Induction of FosB and REM2, but not $c$-Fos by MDMA is blocked by SL327, a specific inhibitor of ERK phosphorylation (Salzmann et al, 2006).

The purpose of this study was to identify the role of FosB in response to METH. Our working hypothesis was that the ERK/calcium-c-Fos/FosB-Sprouty/RGK intracellular signaling acts as a general negative feedback loop for ERK activation and calcium influx in stimulated neurons. If this is true for METH-activated neurons, the Fos $B(-I-)$ mice would show enhanced cellular, neurochemical, and behavioral responses to METH, and decreased Sprouty/RGK expression profiles. We found that $\operatorname{Fos} B(-I-)$ mice indeed showed greater neuronal degeneration in cortices and the striatum, increased incidence of self-injuries, altered regulation of intracellular Sprouty and RGK family transcripts compared with those of their wild-type littermates. In addition, Fos $B(-/-)$ mice showed signs of astroglial dysfunction, reflected as perturbed regulation in brain amino-acid contents and METH-induced BBB disruption.

\section{MATERIALS AND METHODS}

\section{Animals}

All animal experiments were approved by the animal experiment committee of RIKEN. Wild-type C57BL/6J mice were purchased from Japan SLC (Hamamatsu, Japan). The Fos $B(-I-)$ mouse strain was obtained from the Jackson Laboratory (strain C; 129S-Fosb tm $1 M e g / \mathrm{J}$ ). All of the mice were backcrossed at least five times to $\mathrm{C} 57 \mathrm{BL} / 6 \mathrm{~J}$ and generated by $\operatorname{Fos} B(+/-)$ intercrosses. Mice were housed in ventilated shoebox cages $(267 \times 483 \times 152 \mathrm{~mm})$ with access to food and water ad libitum and were maintained under a $12: 12 \mathrm{~h}$ light/dark cycle. TEK-Fresh Standard (Harlan, Madison, WI, USA) bedding was used for animal housing. All mice used in this study were adult males of 10-20 weeks of age, and studies included age-matched controls. Four 
separate groups of $\operatorname{Fos} B(-/-)$ and $(+/+)$ mice were used in the following four major sets of studies: (1) histological studies, (2) hyperthermia, (3) gene expression, and (4) locomotor activity/analysis of brain biogenic amine and amino-acid content. The effects of METH on self-injury were observed across studies except in experiment 4 . Mice were single-housed in clean cages at least 1 day before METH administration, except in experiment 4, where mice remained group-housed throughout.

\section{Overview of METH Treatment Regimens Used}

For histological studies of METH-induced neuronal damage, we gave mice four injections of $10 \mathrm{mg} / \mathrm{kg} \mathrm{METH}$ (methamphetamine hydrochloride, uncorrected for molecular salt and water content; Dainippon Pharmaceuticals, Tokyo, Japan) at 2-h intervals or saline vehicle subcutaneously $(10 \mathrm{ml} / \mathrm{kg})$. These mice were transcardially perfused 3 days later, as previous reports suggest that this time point is where peak neuronal degeneration is observed (Eisch et al, 1998). Mice studied for the hyperthermic effects of METH were administered the same regimen as the histological studies. For the gene expression study, mice were given a single $10 \mathrm{mg} / \mathrm{kg}$ injection of $\mathrm{METH}$ and killed by cervical dislocation $2 \mathrm{~h}$ later, as changes in FosB protein levels and gene expression have been reported to peak about $2 \mathrm{~h}$ after METH stimulation (Cadet et al, 2002; Hiroi et al, 1997). For locomotor activity and analysis of brain biogenic amine and amino-acid content, mice were first administered a $1.5 \mathrm{mg} / \mathrm{kg}$ dose of METH. On the following day, the mice were administered $10 \mathrm{mg} / \mathrm{kg}$ METH four times every $2 \mathrm{~h}$. After 2 days, the mice were administered another $1.5 \mathrm{mg} / \mathrm{kg} \mathrm{METH}$. More detailed descriptions of the treatment regimens and rationales are provided in the appropriate sections below.

\section{Temperature Measurement}

Core body temperature was recorded using a Bat-10 thermometer equipped with a RET-3 mouse rectal probe (Physitemp Inc., Clinton, NJ, USA). It has been reported that c-Fos (-I-) mice are more susceptible to rectal injury and are more prone to fatality by repeated rectal temperature measurements in conjugation with METH administration (Deng et al, 1999). Nonetheless, FosB (-l-) mice were not significantly susceptible to this protocol compared to $\operatorname{Fos} B(+/+)$ mice (data not shown).

\section{Behavior and Self-Injury After METH Administration}

At $30 \mathrm{~min}$ following the first $10 \mathrm{mg} / \mathrm{kg} \mathrm{METH}$ injection, we briefly observed the subject mice from outside the cage. All of the mice showed at least one of the following behaviors: stereotypic sniffing, vigorous chewing, increased locomotor activity, head-bobbing, and excessive salivation, as previously described (Eisch et al, 1998; Wagner et al, 2004). These observations were subjective and qualitative, but not quantitative, as the purpose of the observation was to confirm the proper METH injection. At $2 \mathrm{~h}$ after the injection, we carefully sought evidence of bleeding on the bedding. Whenever signs of bleeding were observed, mice were further examined to identify skin lesions. We repeated this survey just before each subsequent injection to seek for self-injury inflicted after the previous injection. Right after each injection, we confirmed that there was no immediate blood leakage from the injection site itself. A single mouse that showed immediate bleeding from the injection site was excluded from the experiment. Throughout this study, we did not observe any major convulsions in either genotype, though our rudimentary observation scheme may have been insufficient to detect minor convulsions.

\section{Histological Analyses}

At 3 days after the four injections of $10 \mathrm{mg} / \mathrm{kg} \mathrm{METH}$ at 2-h intervals, we anesthetized and perfused mice with $4 \%$ paraformaldehyde in sodium phosphate-buffered saline at $\mathrm{pH}$ 7.4. Brains were postfixed and cryosectioned at $40 \mu \mathrm{m}$. Every fifth serial coronal section was used for tyrosine hydroxylase immunostaining, mouse IgG immunostaining, Fluoro-Jade B (FJB) staining, TdT-mediated dUTP-biotin nick-end labeling (TUNEL) method, or cleaved caspase-3 immunodetection. Although the TUNEL method is a widely used and well-established assay to detect apoptotic cells by labeling double-stranded DNA fragmentation, immunodetection of cleaved caspase- 3 is more specific and sensitive to apoptotic cells (Gown and Willingham, 2002). FJB is a fluorescent dye that has a high affinity for degenerating neurons, regardless of the specific insult or mechanism of cell death (Schmued and Hopkins, 2000).

Indirect immunohistochemical analyses of free-floating brain sections were performed essentially as described (Berghorn et al, 1994; Kuroda et al, 2008). Briefly, brain sections were incubated overnight with a primary antibody and then incubated with the appropriate biotin-conjugated secondary antibody (Vector, Burlingame, CA, USA). The signal was intensified and visualized using a Vectastain Elite $\mathrm{ABC}$ kit and a diaminobenzidine substrate kit (Vector). Sections were mounted on gelatin-coated slides. Bright-field images were acquired using a digital camera DXM1200C and an Eclipse 80i microscope (Nikon, Kawasaki, Japan). The primary antibodies used in this study were an anti-tyrosine hydroxylase mouse monoclonal antibody (1:18 000, MAB318; Chemicon, Temecula, CA, USA) and an anti-cleaved caspase3 rabbit polyclonal antibody (1:500, ASP175; Cell Signaling, Danvers, MA, USA; data not shown).

To measure the relative intensity of tyrosine hydroxylase immunoreactivity, we used bright-field images of 4-6 brain sections between anterior-posterior positions (AP) +1.5 to $+0.8 \mathrm{~mm}$ relative to bregma (Franklin and Paxinos, 2007). Rectangular areas of the images of tyrosine hydroxylase immunostaining in the dorsal striatum (randomly taken from the caudate putamen) and the ventral striatum (taken from the nucleus accumbens core) from each photomicrograph were collected. The size of the rectangular field was varied to cover the maximum amount of the anatomical region of interest, but not any adjacent areas. The optical density (arbitrary units) of these areas was quantified using Scion Image software version 4.0.3 (Scion Corporation, Frederick, MD, USA) by an experimenter blind to the experimental groups. The optical density of immunostaining in the corpus callosum was subtracted as background. The relative density of the dorsal or ventral striatum was 
then averaged in each animal and subjected to statistical analysis.

Evaluation of BBB integrity using IgG immunoreactivity was performed essentially as described (Bowyer and Ali, 2006a; Bowyer et al, 2008). Briefly, the same staining protocol as the tyrosine hydroxylase immunostaining was applied, except that sections were directly incubated with a biotin-conjugated anti-mouse IgG secondary antibody $(1: 2000$; Vector) after the blocking step. We confirmed the previous finding that IgG immunoreactivity in the cortex and striatum after neurotoxic METH treatment was confined to perivascular tissue and weakly in microglial cells (Bowyer et al, 2008). To quantify the extent of IgG extravasation, we used bright-field images of $8-10$ brain sections between AP +1.2 to $-0.7 \mathrm{~mm}$. The numbers of discrete cross-sections of blood vessels surrounded by IgG immunostaining were manually counted. We attempted to omit microglia-like IgG-positive cells from the counts, though some minor ambiguities may have been introduced. As a precaution, we therefore designated these as ' $I g G$ immunoreactive bodies' according to a previous study (Bowyer and Ali, 2006a). The density of IgG immunoreactive bodies was averaged in each brain area of individual animals and subjected to statistical analysis.

Detection of degenerating neurons by FJB staining was performed essentially as described (Schmued and Hopkins, 2000). Briefly, the adjacent serial sections used for IgG immunohistochemistry were mounted on gelatin-coated slides and dried at room temperature. Slides were washed with distilled water for $10 \mathrm{~min}$, gently shaken in $0.06 \%$ potassium permanganate for $15 \mathrm{~min}$, and washed in distilled water again for $1 \mathrm{~min}$. Slides were then gently shaken in $0.0005 \%$ FJB (Histo-Chem Inc., Jefferson, AR, USA) and $0.1 \%$ acetic acid solution for $30 \mathrm{~min}$ in the dark, washed in distilled water, and air-dried in the dark. The slides were dehydrated and coverslipped, and observed as described above, except fluorescent microscopy was applied. The same anatomical areas were observed as in the IgG staining described above. As previously shown, FJB stains the cell bodies, dendrites, axons and axon terminals of degenerating neurons but does not stain healthy neurons, myelin, vascular elements, or neuropil (Schmued and Bowyer, 1997; Schmued and Hopkins, 2000). In addition, it is known that relatively small morphological differences exist between healthy and degenerating neurons. We therefore identified individual FJB-positive neuronal cell bodies by neuronal morphology and counted them manually using the acquired images of each brain area. The density of FJBpositive neurons was averaged in each brain area of individual animals and subjected to statistical analysis.

\section{Quantitative Real-Time PCR (qRT-PCR) Detection of mRNA}

Brain tissue dissections were performed essentially as described (Glowinski and Iversen, 1966) using a mouse brain atlas (Franklin and Paxinos, 2007). Briefly, animals were killed by cervical dislocation and decapitated. After the skin on the skull was removed, the head was chilled in icecold saline for $2 \mathrm{~min}$. After the skull was removed, $1 \mathrm{~mm}$ parasagittal cuts starting from AP $+2 \mathrm{~mm}$ (relative to bregma) toward the posterior were carried out on both hemispheres using a scalpel. Then $\mathrm{AP}+2$ and $+3 \mathrm{~mm}$ coronal cuts were carried out, and the resultant coronal section was placed on saline-soaked filter paper on ice. After removing tissue ventral to the rhinal fissure, the resultant rostral-most cerebral cortical tissue (designated as 'frontoparietal cortex' in this study for simplicity) was collected into $2 \mathrm{ml}$ tubes containing $1.2 \mathrm{ml}$ Trizol reagent (Invitrogen, Carlsbad, CA, USA) on ice. The tissue was homogenized immediately by passing through a 20-gauge needle 20 times and then through a 26-gauge needle 10 times using a $1 \mathrm{ml}$ syringe. For striatal tissue preparation, the lateral hemispheres separated by the parasagittal cuts were soaked in ice-cold saline for $2 \mathrm{~min}$. The striatum was then separated from the cortex by inserting a spatula into the border between the striatum and the external capsule from anterior to posterior using a scooping motion. Finally, the tissue ventral to the anterior commissure was removed, and the resultant bilateral tissue (designated as 'striatum' in this study) was collected and homogenized in Trizol in the same manner as the frontoparietal cortex. To minimize the duration from the animal decapitation to complete tissue homogenization, three experimenters performed this procedure.

Total RNA from the striatum and the frontoparietal cortex was isolated using Trizol and further purified by RNeasy Micro kit (Qiagen, Hilden, Germany). qRT-PCRs were performed with an ABI Prism 7000 Sequence Detector Systems (Applied Biosystems, Foster City, CA, USA) as previously described (Kuroda et al, 2007). The relative amount of specific mRNA was calculated as $2^{(\mathrm{Ct}(\text { each gene) }-\mathrm{Ct}}$ $(G A P D H))$ in triplicate. The average $C_{\mathrm{t}}(G A P D H)$ did not differ between groups (data not shown). The TaqMan probe IDs unique to this study were Mm00494584_ml (GEM), Mm 00600529_m1 (REM2), Mm 00442344_m1 (SPRY2), and Mm 00442345_01 (SPRY4).

\section{Locomotor Assays}

To determine the effect of the neurotoxic schedule of METH administration on the psychomotor effects of a low $(1.5 \mathrm{mg} / \mathrm{kg})$ dose METH administration, we administered to a cohort of mice the same neurotoxic regimen of METH described above, preceded and followed by low-dose administrations of METH, during which locomotion was measured. Thus, all animals were group-housed before and throughout this part of the study except for during locomotor monitoring. On the first day, all mice were given a single subcutaneous injection of $1.5 \mathrm{mg} / \mathrm{kg}$ METH or saline before being individually placed in a $25 \times 25 \times 38.5 \mathrm{~cm}$ locomotormonitoring apparatus (Truscan, Coulbourn Instruments, Allentown, PA) for $45 \mathrm{~min}$. The following day, mice were given four serial injections of $10 \mathrm{mg} / \mathrm{kg}$ METH or saline at 2-h intervals in the home cage. Mice were undisturbed on day 3. On the fourth day, all mice were administered $1.5 \mathrm{mg} / \mathrm{kg}$ METH or saline, and locomotion was monitored for $45 \mathrm{~min}$.

\section{Biochemical Analyses of Tissue Biogenic Amine and Amino-Acid Contents}

To investigate the effect of the neurotoxic schedule of METH administration on central biogenic amine systems, 
the same cohorts of mice used in the locomotor assay study were killed immediately following the locomotormonitoring session on the fourth day by decapitation. The brains were rapidly removed and frozen on crushed dry ice before storage at $-80^{\circ} \mathrm{C}$. This strategy was chosen to minimize the number of animals required for the overall study, even though this strategy led to the caveat that the results from this part of the study were not directly comparable with the hyperthermia, immunoreactivity, and FJB studies described above, as they received marginally higher $(7.5 \%$ more in terms of quantity) exposure to METH.

Coronal sections $(150 \mu \mathrm{m})$ were prepared on a cryostat and mounted immediately onto gelatinized slides. Using a $1 \mathrm{~mm}$ diameter biopsy punch (Kai Medical, Gifu Prefecture, Japan), we took circular tissue punches from the frontoparietal cortex, dorsal, and ventral striatum. A total of 5, 12, and 10 punches were pooled by region from the frontoparietal cortex (AP coordinates $5.90-5.34 \mathrm{~mm}$ interaurally, according to the atlas (Franklin and Paxinos, 2007)), dorsal striatum (4.90-3.82 $\mathrm{mm})$ and ventral striatum (5.14$4.18 \mathrm{~mm}$ ), respectively of individual mice. Samples were immediately stored at $-80^{\circ} \mathrm{C}$ until further analysis.

The biochemical contents of the tissue were assayed as previously described (Katayama et al, 2008) by highpressure liquid chromatography (HPLC) coupled to either electrochemical detection (for biogenic amines) or fluorometric detection following derivatization with $o$-phthaldehyde (for amino acids). Briefly, extracts from the tissue punches were obtained by sonication at $4^{\circ} \mathrm{C}$ in $60 \mu$ of extraction buffer for the frontoparietal cortex or $100 \mu \mathrm{l}$ for the dorsal and ventral striatum. The extraction buffer consisted of perchloric acid $(0.1 \mathrm{M})$ and isoproterenol $(200 \mathrm{nM})$ or L-norleucine $(200 \mu \mathrm{M})$ as internal standards for monoamine and amino-acid analyses, respectively. The amino-acid standards used were composed of the L-type stereoisomers (H-type standard; Wako Pure Chemicals, Japan with additional L-type amino acids and $\gamma$-aminobutyric acid (GABA) standards incorporated). A commercial protein assay kit (Bio-Rad, Hercules, CA) was used to determine the protein content of the extracts. Turnover rates were calculated as follows: $\mathrm{DA}$ turnover rate $=$ $(\mathrm{DOPAC})+(\mathrm{HVA}) /(\mathrm{DA}) ; 5$-HT turnover rate $=(5$-HIAA $) /$ (5-HT).

\section{Statistical Analyses}

For the statistical analysis of the data, various analyses of variance (ANOVAs) and Fisher's exact probability tests were applied where appropriate (see Results section). Significance levels were set at $p<0.05$ (two tailed). Statistical analyses were performed using SPSS 10.0 for Windows (SPSS Japan, Tokyo, Japan) or StatView (StatView, Berkley, CA). All data are expressed as mean \pm standard error of the mean (SEM).

\section{RESULTS}

\section{Enhanced METH Neurotoxicity in FosB(-I-) Mice}

To test whether FosB $(-/-)$ neurons exhibit enhanced vulnerability to METH-induced excitotoxicity, we used a neurotoxic regimen of four injections of $10 \mathrm{mg} / \mathrm{kg}$ METH spaced at 2-h intervals as previously described (Eisch et al, 1998; Deng et al, 1999; Kita et al, 2003). FosB(+/+) and $(-I-)$ mice were killed 3 days later and examined for neurodegeneration by FJB labeling. FJB is a fluorescent dye that has high affinity for degenerating neurons, regardless of specific insult or mechanism of cell death (Schmued and Hopkins, 2000). Consistent with previous reports (Ryan et al, 1990; Schmued and Bowyer, 1997; Deng et al, 2001), neurodegeneration occurred in the frontoparietal and piriform cortices and in the striatum (Figure 1a), in METH-treated both Fos $B(+/+)$ and $(-/-)$ mice. We found some FJB-positive neurons in the hippocampal complex as well, but to a much lesser extent (data not shown). In both Fos $B(+/+)$ and $(-/-)$ saline-treated animals, FJB-positive neurons were rarely found in any brain area (Figure 1b).

The densities of FJB-positive degenerating neurons were quantified and analyzed by a two-way ANOVA with intersubject factors of genotype and treatment (Figure $1 \mathrm{~b}$ ). Significant effects of treatment were found in the frontoparietal cortex $\left(\mathrm{F}_{1,18}=24.84, p<0.001\right)$, striatum $\left(\mathrm{F}_{1,18}=\right.$ $5.00, p=0.038)$, and piriform cortex $\left(\mathrm{F}_{1,18}=8.40, p=\right.$ $0.010)$. Significant effects of genotype were found in the frontoparietal cortex $\left(\mathrm{F}_{1,18}=15.32, p=0.001\right)$ and striatum $\left(\mathrm{F}_{1,18}=4.61, p=0.046\right)$, but not in the piriform cortex $\left(\mathrm{F}_{1,18}=2.06, \quad p=0.169\right)$. Significant genotype-treatment interactions were found in the frontoparietal cortex $\left(\mathrm{F}_{1,18}=15.37, \quad p=0.001\right)$ and striatum $\left(\mathrm{F}_{1,18}=4.59\right.$, $p=0.046)$, but not in the piriform cortex $\left(\mathrm{F}_{1,18}=2.07\right.$, $p=0.168)$. After METH treatment, therefore, the frontoparietal cortex and striatum of $\operatorname{Fos} B(-/-)$ mice contained significantly more FJB-positive neurons than those of their $\operatorname{Fos} B(+/+)$ littermates. In contrast, we did not find a significant genotype-treatment interaction in the piriform cortex, possibly because there was large individual variability in the number of degenerating neurons in both $(-/-)$ and $(+/+)$ mice. These data suggested that FosB protects neurons in the frontoparietal cortex and striatum from METH-induced neurotoxicity.

FJB-positive cells tended to cluster in subregions. In the parietal cortex, most of the degenerating cells were layer-III pyramidal neurons and superficial layer-IV multipolar neurons in the parietal cortex area 1 , as previously described (Eisch et al, 1998). Moreover, FJB-positive cells tended to be found in the very center of the striatum. In the piriform cortex, the FJB-positive cells were clustered in the dorsal endopiriform area. These distribution patterns of FJB-positive neurons are the same in both genotypes. Notably, these distribution patterns were very similar to the area of BBB dysfunction identified and described below.

We also sought evidence of differences in the amount of apoptosis by means of the TUNEL histochemical method and anticleaved caspase- 3 immunodetection method. We observed much smaller numbers of apoptotic neurons by either anticleaved caspase-3 immunoreactivity or the TUNEL method in forebrain regions 3 days after four $10 \mathrm{mg} / \mathrm{kg}$ injections in both Fos $B(-/-)$ and $(+/+)$ mice compared with the numbers of FJB-positive neurons (data not shown). Thus, under our experimental conditions, it appeared that METH-induced neuronal death in $\operatorname{Fos} B(-I-)$ mice was largely due to necrosis or some other nonapoptotic regulated death program. 

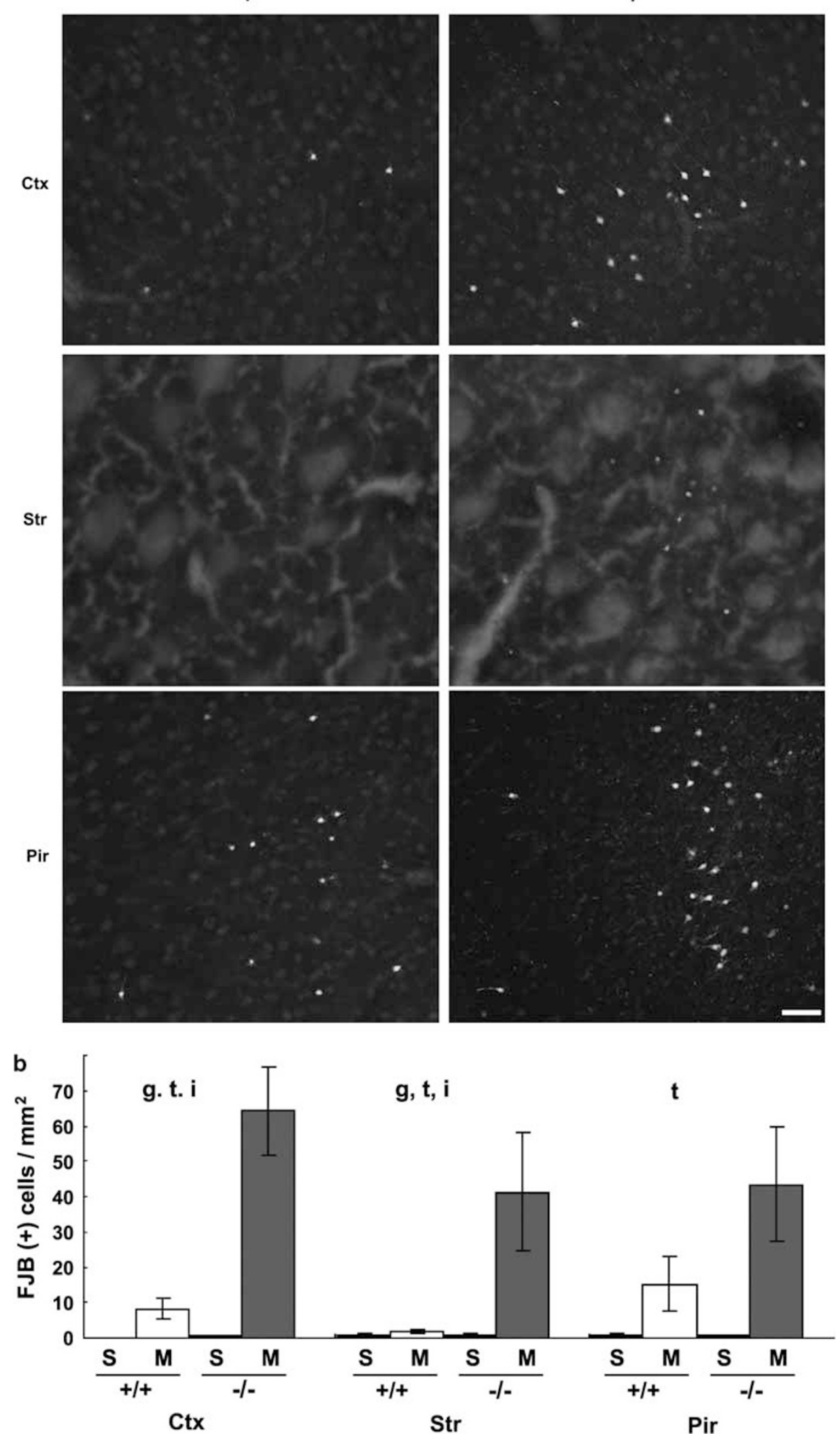

Figure I Effects of the FosB mutation on neurodegeneration after neurotoxic methamphetamine $(\mathrm{METH})$ administration. FosB $(+/+)$ and $(-/-)$ mice were treated with four injections of saline (S, n=5 each) or $10 \mathrm{mg} / \mathrm{kg} \mathrm{METH}(\mathrm{M}, n=6$ each) and were examined for neurodegeneration 3 days later by Fluoro-Jade B (FJB) staining. (a) Fluorescent microscopy of fields from the parietal cortex (Ctx), the striatum (Str), and the piriform cortex (Pir) of METHtreated mice. These areas were taken from the rectangular areas shown in Figure 7a. Scale bar $=100 \mu$ m. (b) Mean \pm SEM density of FJB-positive degenerating cells in each area. Letters above the bars indicate significant effects $(p<0.05)$ of genotype $(g)$, treatment $(t)$, and/or genotype-treatment interaction (i) by a two-way analysis of variance (ANOVA) with the intersubject factors of genotype and treatment. 


\section{No Differences in METH-Induced Hyperthermia in Fos B (-I-) Mice}

Methamphetamine-induced neurodegeneration is mediated at least partly by hyperthermia (Bowyer, 1995). Thus, we examined the core body temperature of $\operatorname{Fos} B(-l-)$ and $(+/+)$ mice during the neurotoxic regimen of METH administration. Using a repeated-measures ANOVA with the intersubject factors of genotype and the within-subject factor of time point, we found a significant effect of time in core body temperature $\left(\mathrm{F}_{10,80}=28.27, p<0.001\right)$ due to a progressive increase in body temperature in both genotypes, which returned to basal levels by the end of the 7-h recording period (Figure 2). No significant effects of genotype were found in core body temperature after METH injection $\left(\mathrm{F}_{1,8}=0.047, p=0.834\right)$. Fos $B(-1-)$ mice therefore did not show altered susceptibility to METH-induced hyperthermia, thus eliminating this factor as the primary cause of enhanced neurodegeneration in these mice.

\section{Increased Incidence of Self-Injury in METH-Treated FosB $(-/-)$ Mice}

It has been reported that high doses of METH induce selfinjurious behaviors in mice, defined as self-biting and scratching that causes breaks in the skin (Kita et al, 2003). We observed signs of bleeding on the cage bedding of some Fos $B(-/-)$ mice after the first $10 \mathrm{mg} / \mathrm{kg}$ METH injection. Five out of eight bleeding $(-/-)$ mice exhibited clear skin lesions (Table 1), mostly with obvious marks of insults by teeth or nails. These skin lesions were attributed to selfinflicted biting and scratching, as mice were single-housed throughout these experiments. It was highly unlikely that these lesions were caused just by falling on or hitting the

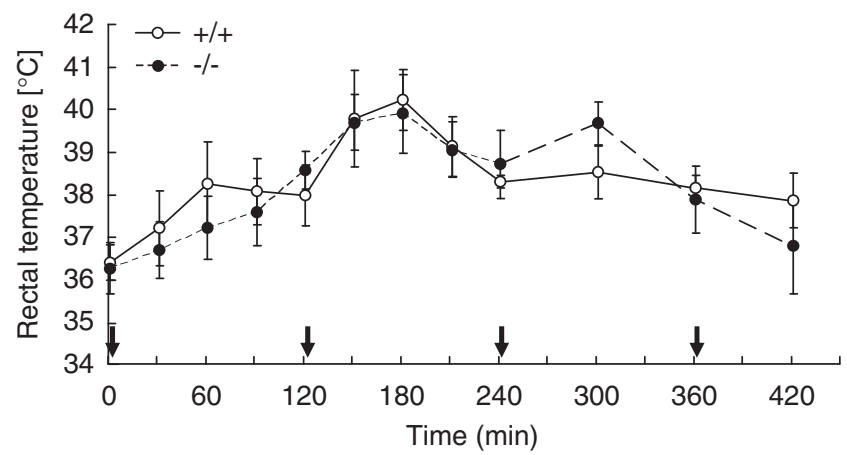

Figure 2 Effects of the FosB mutation on core body temperature during neurotoxic methamphetamine $(\mathrm{METH})$ treatment. Rectal temperature of Fos $B(+/+)$ (open circle, $n=5$ ) and of $(-/-$ ) (closed circle, $n=5$ ) mice was measured during four injections of $10 \mathrm{mg} / \mathrm{kg} \mathrm{METH}$, indicated by arrows. Data are presented as mean \pm SEM. cage wall, the wire lid, water valve, or ventilation nozzle. The locations of the lesions did not show any relationship with the site of METH injection. In the most severe case, an Fos $B(-I-)$ mouse had $0.5 \times 1 \mathrm{~cm}$ detachment of skin from its chest and the ventral part of the neck, and the underlying musculature was exposed. For the remaining three bleeding mice, we were unable to identify any obvious skin lesion, though smaller injuries to the tongue or oral cavity due to oral dyskinesia could have possibly occurred (Wagner et al, 2004). A Fisher's exact probability test showed that Fos $B(-1-)$ mice were significantly more prone to bleeding $(p=0.023)$ and self-injury $(p=0.049)$ compared to their $(+/+)$ littermates after a single $10 \mathrm{mg} / \mathrm{kg}$ METH injection, suggesting that FosB deficiency increases the incidence of METH-induced self-injuries. All incidences of bleeding occurred within $2 \mathrm{~h}$ of the first METH injection. Further extension of injuries was not evident following the second METH injection. Moreover, even the mouse showing the largest lesion survived all four METH injections, and we observed significant healing of the lesion on the fourth day. Thus, it appeared that the METH-induced self-inflicted injuries were largely due to the first METH exposure, rather than being secondary to longer-term neurodegenerative changes.

\section{Altered Expression of Sprouty and RGK in FosB(-I-) Mice}

We have previously shown that, during parental care, ERK induces $F o s B$, and FosB then exerts its effect to induce $S P R Y 1$ and $R A D$, both of which are negative feedback regulators for neuronal activation (Kuroda et al, 2007). We hypothesized that a similar molecular change might occur in some brain areas of FosB $(-/-)$ mice on METH stimulation. Thus, we examined gene expression profiles in the frontoparietal cortex and striatum of $F o s B(+/+)$ and $(-/-)$ mice after a single $10 \mathrm{mg} / \mathrm{kg}$ METH injection by qRTPCR analyses. Preliminary time-course experiments showed that in the frontoparietal cortex of $(+/+)$ mice both SPRY1 and $R A D$ induction were observed $2 \mathrm{~h}$ after METH injection (data not shown). Conversely, neither SPRY1 nor RAD induction was observed in $\operatorname{Fos} B(+/+)$ striatum. As mentioned in the Introduction, both SPRY1 and RAD belong to a family of homologous genes, namely Sprouty and $R G K$, respectively. These homologous transcripts were examined together with SPRY1 and RAD to determine if these family members were induced in the striatum instead.

A two-way ANOVA with the intersubject factors of genotype and treatment confirmed upregulation of immediately early genes ( $c$-Fos, FosB, and NGFI-B) by METH treatment in both the frontoparietal cortex $\left(\mathrm{F}_{1,20}=16.78\right.$, 27.42 , and 68.60 , respectively, $p<0.001$ for all) and striatum

Table I Effects of the FosB Mutation on the Incidence of Bleeding and Skin Lesions $2 \mathrm{~h}$ After a $10 \mathrm{mg} / \mathrm{kg}$ METH Injection

\begin{tabular}{lllrr}
\hline & No bleeding & Bleeding of unknown origin & Bleeding with skin lesion \\
\hline$+/+$ & Saline & $22(100 \%)$ & $0(0 \%)$ & $0(0 \%)$ \\
$-1-$ & $22(96 \%)$ & $0(0 \%)$ & $1(4 \%)$ & $0(0 \%)$ \\
& Methamphetamine & $22(100 \%)$ & $0(0 \%)$ & 22 \\
& Saline & $16(67 \%)$ & $3(13 \%)$ & 22 \\
\hline
\end{tabular}


Frontoparietal cortex

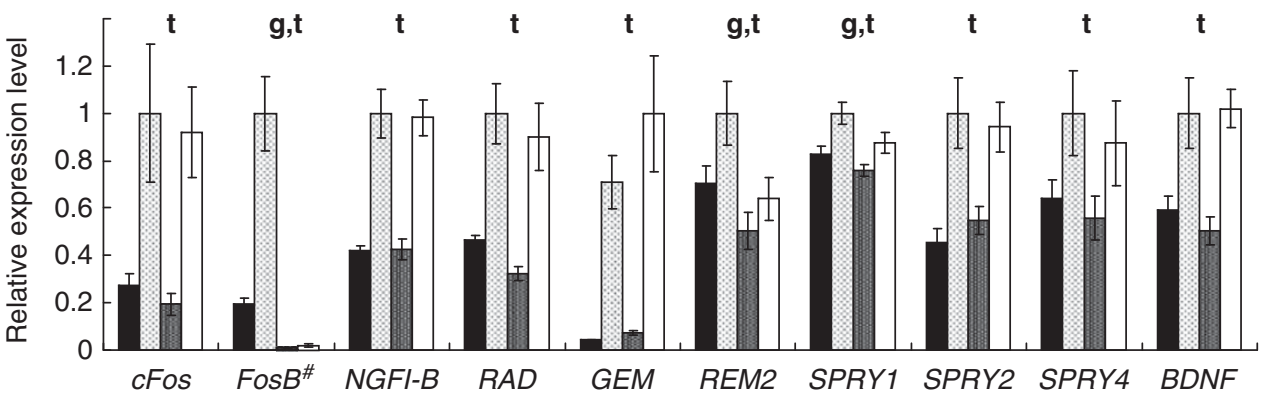

Striatum

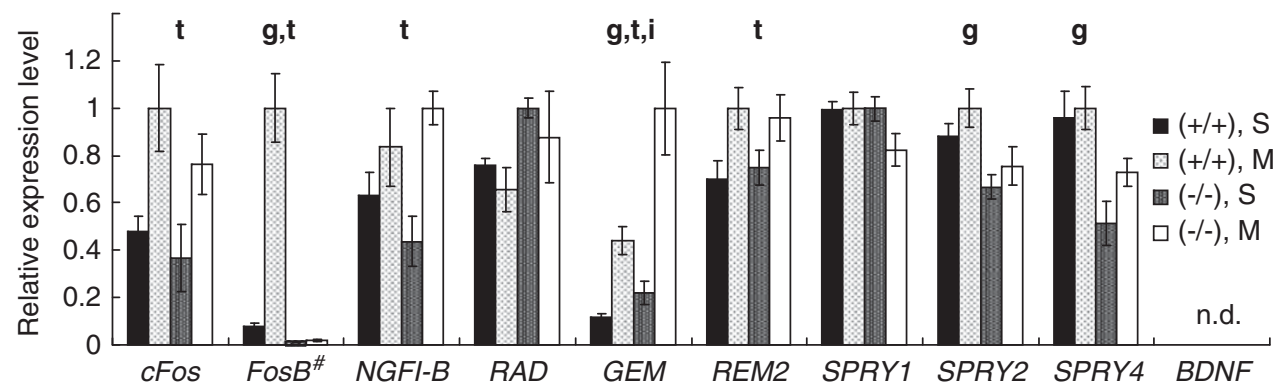

Figure 3 Effects of the FosB mutation on gene expression in the frontoparietal cortex and striatum $2 \mathrm{~h}$ after a single $10 \mathrm{mg} / \mathrm{kg}$ methamphetamine (METH) injection. Mean \pm SEM relative gene expression levels in the frontoparietal cortex or in the striatum examined by qRT-PCR. Fos $B(+/+)$ and $(-/-)$ mice were treated with either a single saline $(S)$ or a $10 \mathrm{mg} / \mathrm{kg}$ METH $(\mathrm{M})$ injection, and tissue was dissected $2 \mathrm{~h}$ after injection ( $n=6$ per group). Data are expressed as arbitrary units normalized to GAPDH, with highest values within a group set to I. Letters above the bars indicate significant effects $(p<0.05)$ of genotype $(\mathrm{g})$, treatment $(\mathrm{t})$, and/or genotype-treatment interaction (i) by a two-way analysis of variance (ANOVA) with the intersubject factors of genotype and treatment. \#genotype-treatment interaction was not statistically analyzed due to lack of FosB transcripts in FosB $(-/-)$ mice; n.d., not reliably detected.

$\left(\mathrm{F}_{1,20}=11.29,40.48\right.$, and 11.03; $p=0.003,<0.001$, and 0.003 , respectively, Figure 3) as previously reported (Graybiel et al, 1990; Herdegen and Leah, 1998). Notably, in the frontoparietal cortex, all the Sprouty family genes $\left(\mathrm{F}_{1,20}=14.45,22.02\right.$, and $5.81 ; p=0.001,<0.001$, and 0.026 for $S P R Y 1,2$, and 4 , respectively) and all $R G K$ family genes tested $\left(\mathrm{F}_{1,20}=33.15,34.99\right.$, and $4.98 ; p<0.001,<0.001$, and 0.037 for $R A D, G E M$, and REM2, respectively) were significantly induced by METH treatment. Brain-derived neurotrophic factor (BDNF) was also upregulated by METH treatment in the frontoparietal cortex $\left(F_{1,20}=23.65\right.$, $p<0.001$; Figure 3 ), similar to previous reports for cocaine treatment (Le Foll et al, 2005). These findings were consistent with the previously suggested cellular functions of Sprouty and RGK proteins as negative feedback regulators of BDNF-RTK-ERK/calcium signaling during neuronal activation (Kelly, 2005; Kuroda et al, 2007; Mason et al, 2006). In the striatum, GEM $\left(\mathrm{F}_{1,20}=27.34, p<0.001\right)$ and REM2 $\left(\mathrm{F}_{1,20}=9.15, p=0.006\right)$ were induced, but not Sprouty $\left(\mathrm{F}_{1,20}=3.66,2.28\right.$, and $2.04 ; p=0.07,0.14$, and 0.17 , for $S P R Y 1,2$, and 4 , respectively) by the METH treatment used. Expression of BDNF was about 1000 times lower than that in the frontoparietal cortex, and was too low to be reliably measured under our experimental conditions. This suggests that a different signaling mechanism exists in the frontoparietal cortex and in the striatum.

As expected, there was a clear absence of FosB expression in Fos $B(-/-)$ mice (significant genotype effects of $\mathrm{F}_{1,20}=50.98,51.73$ for the frontoparietal cortex and striatum, respectively; $p<0.001$; Figure 3 ), confirming ablation of the FosB gene. A two-way ANOVA showed significant genotype-dependent effects on REM2 $\left(\mathrm{F}_{1,20}=8.30, p=0.009\right)$ and SPRY1 $\left(\mathrm{F}_{1,20}=6.26, p=0.02\right)$ expression in the frontoparietal cortex, and on GEM $\left(\mathrm{F}_{1,20}=9.89, p=0.005\right)$, SPRY2 $\left(\mathrm{F}_{1,20}=10.89, p=0.004\right)$, and SPRY4 $\left(\mathrm{F}_{1,20}=15.43, p=0.001\right)$ in the striatum (Figure 3). A significant genotype-treatment interaction was found for GEM $\left(\mathrm{F}_{1,20}=9.89, p=0.005\right)$ in the striatum. Except for $G E M$, all of these changes showed a reduction in Sprouty and RGK genes, and no significant genotypetreatment interaction was found. Thus, FosB appears to regulate the basal expression of these genes. Unexpectedly, GEM induction was enhanced in FosB $(-/-)$ mice compared with their $(+/+)$ littermates (see Discussion). Taken together, these results suggest that many of Sprouty and RGK family members are induced by METH treatment in $F o s B(+/+)$ mice, and expression of REM2 and SPRY1 in the frontoparietal cortex and expression of SPRY2 and 4 in the striatum depended at least partially on FosB.

\section{Effect of the Null Mutation of FosB on Dopaminergic Terminal Degeneration After Neurotoxic METH Treatment}

FosB has been implicated in drug addiction and regulation of the mesolimbic dopaminergic system (Nestler, 2001). For example, previous studies have shown that $\mathrm{Fos} B(-/-)$ mice are hypersensitive to the psychomotor actions of cocaine (Hiroi et al, 1997). These previous reports suggest that the histological and behavioral METH hypersensitivity of FosB $(-/-)$ mice could be due to the hypersensitivity of the dopaminergic system to psychostimulants in FosB $(-/-)$ 


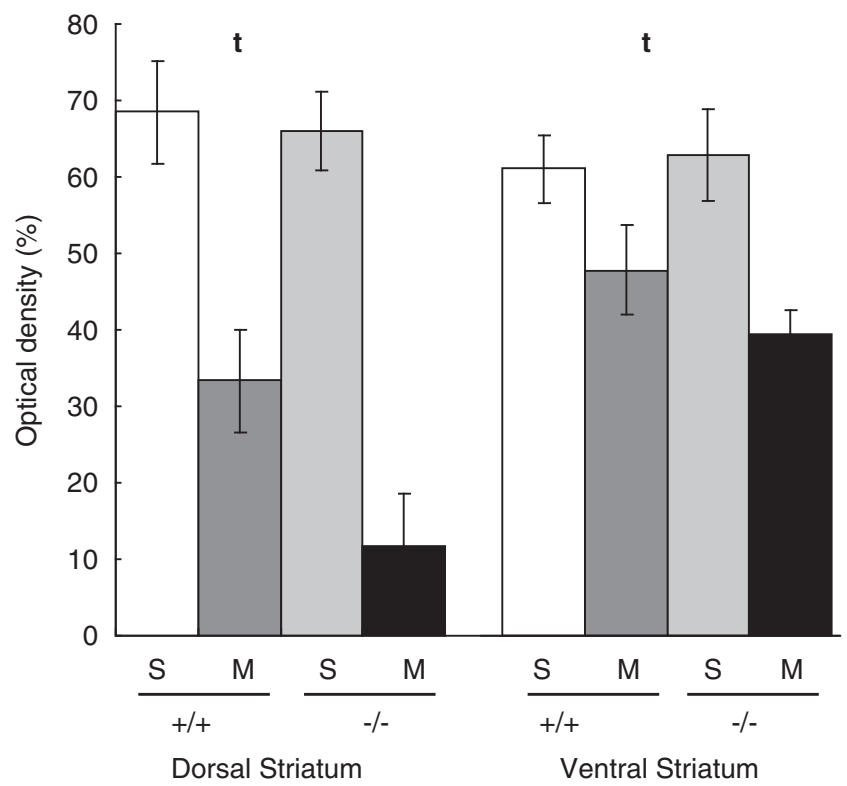

Figure 4 Effects of the FosB mutation on striatal tyrosine hydroxylase immunoreactivity in response to neurotoxic methamphetamine (METH) administration. Mean \pm SEM optical density of tyrosine hydroxylaseimmunopositive fibers in the dorsal and ventral striatum. FosB $(+/+)$ and $(-/-)$ mice $(n=5-6)$ were treated with four injections of saline $(S)$ or $10 \mathrm{mg} / \mathrm{kg}$ METH (M) spaced $2 \mathrm{~h}$ apart and were examined for tyrosine hydroxylase immunoreactivity 3 days later. Further details are described in the Materials and methods section. Letters in charts indicate significant effects $(p<0.05)$ of treatment (t) by a two-way analysis of variance (ANOVA) with the intersubject factors of genotype and treatment.

mice. To test this, we first examined the density of tyrosine hydroxylase-immunopositive dopaminergic fibers in the dorsal (caudate putamen) and ventral striatum (nucleus accumbens) (Figure 4) using tissue obtained from the same mice as those studied for FJB staining in Figure 1, which had been treated with four $10 \mathrm{mg} / \mathrm{kg}$ administrations of METH at 2-h intervals. A two-way ANOVA with the intersubject factors of genotype and treatment confirmed significant decreases in tyrosine hydroxylase immunoreactivity following METH treatment in both the dorsal $\left(\mathrm{F}_{1,18}=47.53\right.$, $p<0.001)$ and ventral striatum $\left(\mathrm{F}_{1,18}=13.69, p=0.002\right)$ as previously reported (McCann and Ricaurte, 2004). No significant effects of genotype, however, were found in either dorsal $\left(\mathrm{F}_{1,18}=3.41, p=0.81\right)$ or ventral striatum $\left(\mathrm{F}_{1,18}=0.44, p=0.52\right)$. Moreover, no significant genotypetreatment interactions were found either in dorsal $\left(\mathrm{F}_{1,18}=2.19, p=0.157\right)$ or ventral striatum $\left(\mathrm{F}_{1,18}=1.02\right.$, $p=0.326)$. Dopaminergic terminals in Fos $B(-l-)$ striatum were therefore not found to be more vulnerable to METHinduced degeneration than those in $\operatorname{Fos} B(+/+)$ littermates.

\section{Effects of the Null Mutation of FosB on Locomotor Responses to METH After Repeated Treatment}

To test the function of FosB in METH-induced locomotion and neurochemical responses simultaneously, we used the regimen of repeated METH administration detailed in Figure 5a. That is, $\operatorname{Fos} B(-/-)$ and $(+/+)$ mice were subjected to the same regimen of four injections of a high dose $(10 \mathrm{mg} / \mathrm{kg})$ of METH at 2-h intervals used in the histological and hyperthermia studies, but this was flanked
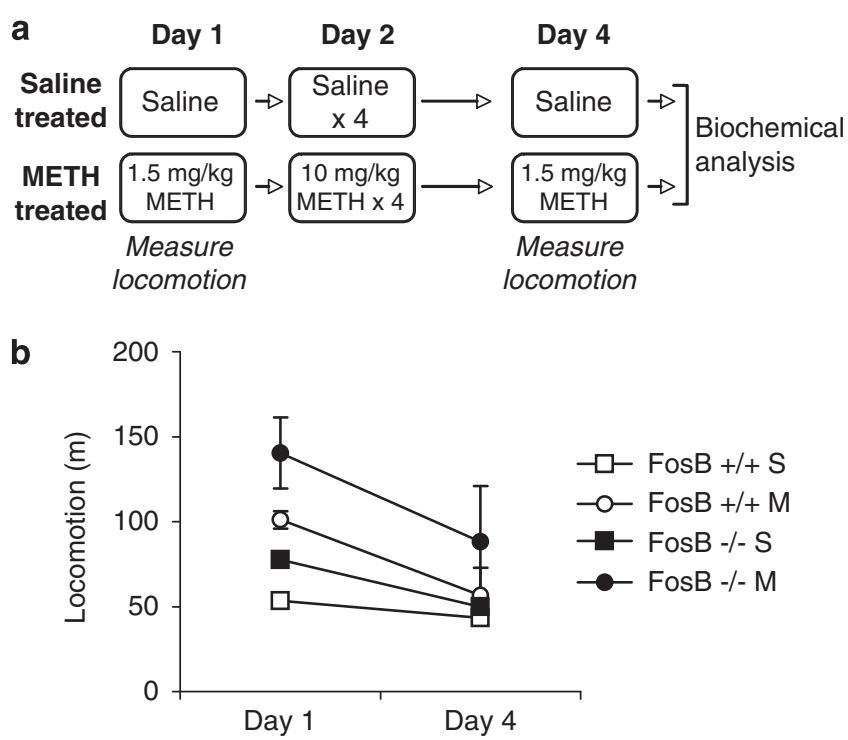

Figure 5 Effects of the null mutation of FosB on locomotor responses to methamphetamine (METH) following repeated treatment. (a) Summary of drug administration protocol used for locomotor and biochemical studies. (b) Horizontal locomotor activity during the $45 \mathrm{~min}$ period following $1.5 \mathrm{mg} / \mathrm{kg}$ METH administrations carried out on days I and 4. Data are presented as mean \pm SEM; $n=5-6$ per group. S, saline treated; M, METH treated. See Results section for statistical analysis.

temporally with two low-dose $(1.5 \mathrm{mg} / \mathrm{kg})$ administrations of METH used to assess the psychomotor properties of METH. For comparison, additional groups of mice were administered saline throughout. A two-way repeatedmeasures ANOVA showed a main effect of genotype $\left(\mathrm{F}_{1,18}=5.58, p=0.030\right)$, METH treatment $\left(\mathrm{F}_{1,18}=18.19\right.$, $p<0.001)$, and time $\left(\mathrm{F}_{1,18}=10.61, p=0.004\right)$ on horizontal locomotion. There were no significant interactions between these factors. The main effects were due to an approximately $40 \%$ higher locomotor activity in $F o s B(-/-)$ mice, as has been previously reported (Hiroi et al, 1997). METH administration stimulated increases in locomotion in both genotypes during both measurements that were approximately equal compared to saline-treated control mice of the same genotype (Figure 5). There was a decrease in locomotor activity in all mice, regardless of treatment between the first (day 1) and second (day 4) locomotion measurements $\left(\mathrm{F}_{1,18}=10.609, \quad p=0.004\right.$, no significant interactions with treatment or genotype). These results indicate that the null mutation of FosB causes a generally enhanced locomotor activity, but does not influence the psychomotor effects of METH at the $1.5 \mathrm{mg} / \mathrm{kg}$ dose administered in this study.

\section{Effects of the Null Mutation of FosB on Biogenic Amines and Amino Acids}

Immediately following the second locomotor measurement, animals were killed and brains were removed for neurochemical analysis. Tissues biopsies were taken from frozen sections of the frontoparietal cortex and the dorsal and ventral striatum, and analyzed by HPLC for biogenic amine dopamine, serotonin and their metabolites, and amino-acid content. For amino acids, we focused our analysis particularly on neuroactive compounds, such as those 
Table 2 Summary of the Effect of the Null Mutation of FosB and METH Administration on Tissue Biochemical Content

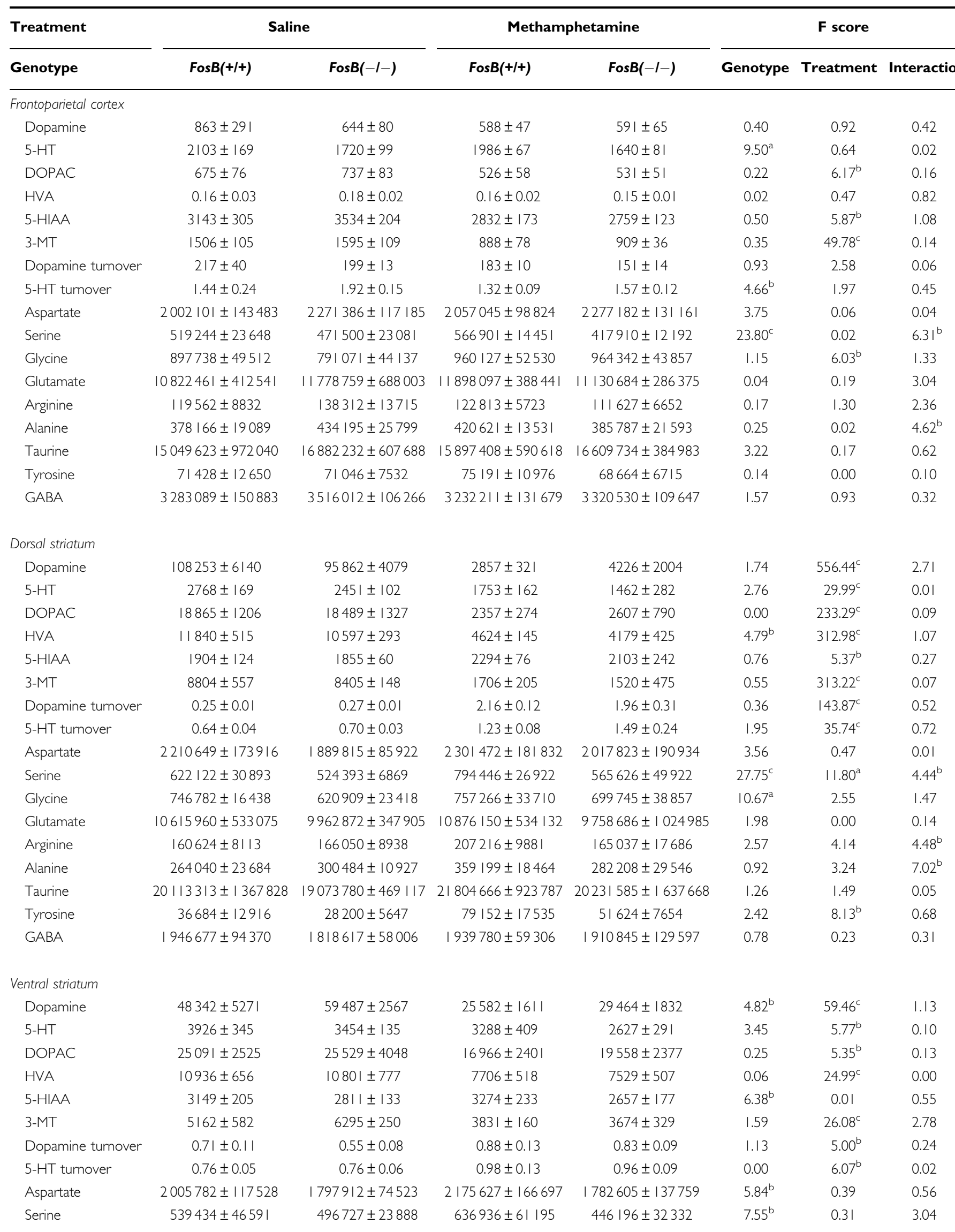


Table 2 Continued

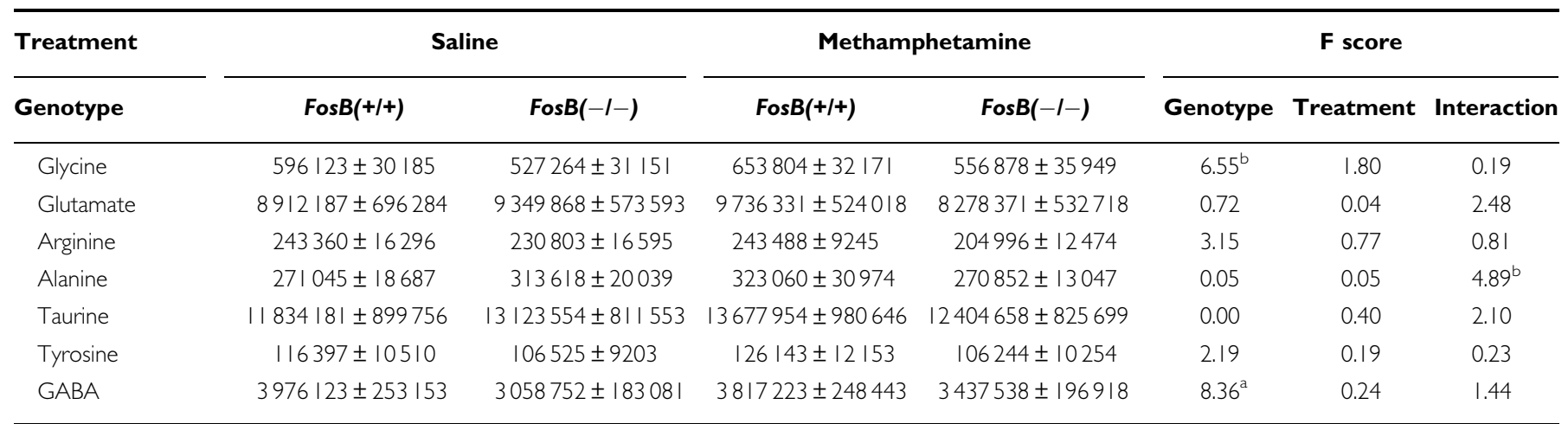

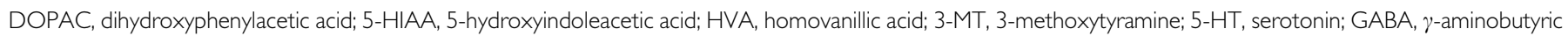
acid.

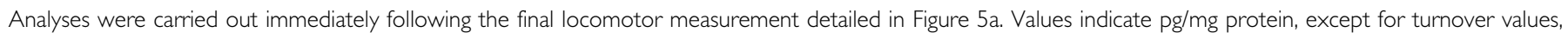
which are presented as ratios as described in the Materials and methods section. Note that there were no genotype- or treatment-dependent effects on tissue protein contents. Data are presented as mean \pm SEM. $n=5-6$ per group. Rightmost columns indicate the result of statistical analysis.

Degrees of freedom are I, 18 in all cases except 3-MT in PFC, which are I, 17 due to a single undetectable sample.

${ }^{a} p<0.01$.

${ }_{p} p<0.05$.

$c_{p}<0.001$.

acting at the glutamate (Glu) site of the $N$-methyl-Daspartate (NMDA) receptor (glutamate and aspartate), at the co-agonist site of the NMDA receptor (glycine), GABA, and arginine, as it is a precursor for nitric oxide synthesis (Sakurai et al, 2004). We also included several amino acids with either putative or unspecified neuroactivity, such as taurine, alanine, and serine. The quantification of amino acids was performed by comparing it to a standard cocktail of L-type amino acids (see Materials and methods for details). The results of the analysis are shown in Table 2 alongside the results of the statistical analyses. Overall, the most pervasive genotype-dependent difference observed was reduced tissue serine content in $F o s B(-/-)$ mice (Figure 6). A two-way ANOVA with the intersubject factors of genotype and treatment showed significant effects of genotype in the serine content in the frontoparietal cortex $\left(\mathrm{F}_{1,18}=23.80, p<0.001\right)$, dorsal striatum $\left(\mathrm{F}_{1,18}=27.75\right.$, $p<0.001)$, and ventral striatum $\left(\mathrm{F}_{1,18}=7.55, p=0.013\right)$. Serine content was consistently lower (approximately $80-$ $90 \%$ of the amount of $F o s B(+/+)$ mice in saline-treated groups, and approximately $70 \%$ in METH-treated groups) in all brain areas of Fos $B(-/-)$ mice. A significant effect of treatment was found in the dorsal striatum $\left(\mathrm{F}_{1,18}=11.80\right.$, $p=0.003$ ), and significant genotype-treatment interactions were found in the frontoparietal cortex $\left(\mathrm{F}_{1,18}=6.31\right.$, $p=0.022)$ and dorsal striatum $\left(\mathrm{F}_{1,18}=4.44, p=0.049\right)$ (Figure 6). Fos $B(-I-)$ mice therefore had lower basal serine levels that did not increase after METH administration. There was a differential effect of METH administration on tissue alanine content between Fos $B(-/-)$ and $(+/+)$ mice (Figure 6). Although there were no significant effects of genotype or treatment in any brain region, significant interactions between genotype and treatment were found in all brain regions $\left(\mathrm{F}_{1,18}=4.62, p=0.045\right.$ in the frontoparietal cortex; $\mathrm{F}_{1,18}=7.02, p=0.016$ in dorsal striatum; and $\mathrm{F}_{1,18}=4.89, p=0.040$ in ventral striatum). Whereas METH treatment stimulated mild increases in alanine content in Fos $B(+/+)$ mice, there was either no change or a decrease in $F o s B(-l-)$ mice. Notably, glycine was significantly lower in both the dorsal $\left(\mathrm{F}_{1,18}=10.67, p=0.0043\right)$ and the ventral striatum $\left(\mathrm{F}_{1,18}=6.55, p=0.0197\right)$ of $\operatorname{Fos} B(-/-)$ mice (Figure 6).

There were several other significant effects of genotype, such as serotonin content in the frontoparietal cortex and GABA content in the ventral striatum (Table 2). All of these changes were due to lower tissue contents in $\operatorname{Fos} B(-/-)$ compared with their $(+/+)$ littermates. It should be noted, however, that no significant effect of genotype or genotypetreatment interaction was found in dopamine or dihydroxyphenylacetic acid (DOPAC) content or in dopamine turnover throughout this analysis, except dopamine content was mildly higher in the ventral striatum of $\operatorname{Fos} B(-1-)$ mice $\left(\mathrm{F}_{1,18}=4.82, p=0.042\right)$. METH treatment induced significant reductions in dopamine and DOPAC content in the ventral and especially the dorsal striatum, as previously reported (Cadet et al, 2003), verifying our experimental procedures.

It is important to note that we did not apply any correction for the multiple comparisons made in the biochemical data presented here, as others have suggested that this may lead one to overlook informative findings (see Curran-Everett, 2000; Perneger, 1998 for discussion). The results, however, should be viewed in this context.

\section{Effect of the Null Mutation of FosB on the BBB Dysfunction After Neurotoxic METH Treatment}

Methamphetamine-induced BBB dysfunction has been suggested as a mean by which METH induces neurotoxicity (Dietrich, 2009). Loss of BBB integrity allows penetration of blood-born macromolecules, such as IgG and albumin, into perivascular tissue (extravasation). IgG extravasation can be detected by IgG immunostaining on brain tissue, even after transcardial perfusion. To assess if $F o s B(-/-)$ mice are especially vulnerable to METH-induced BBB damage, we performed IgG immunohistochemistry on brain sections from mice treated with four $10 \mathrm{mg} / \mathrm{kg}$ METH administrations. The numbers of discrete IgG-immunoreactive bodies 
Frontoparietal

Cortex
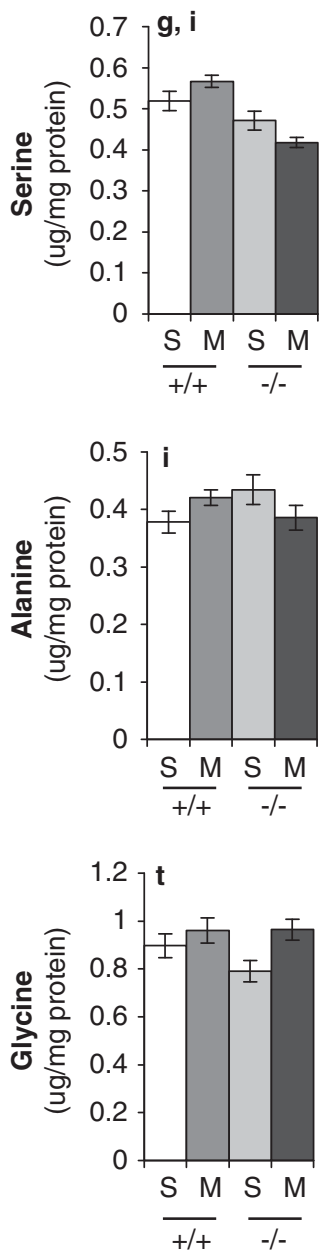
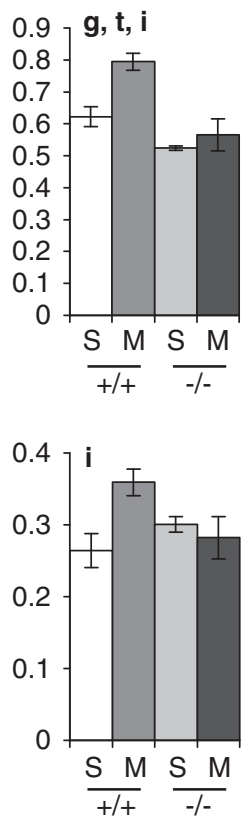

Dorsal

Striatum

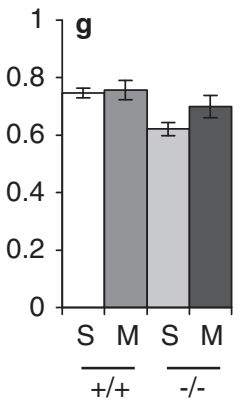

Ventral Striatum
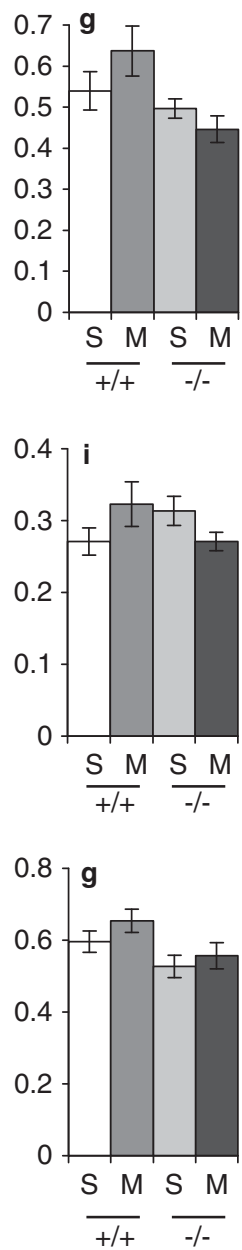

Figure 6 Graphical representation of the effect of the null mutation of Fos $B$ on basal and methamphetamine (METH)-induced changes in tissue serine, alanine and glycine content. Analyses were carried out immediately after the final locomotor measurement detailed in Figure $5 \mathrm{a}$. S, saline treated; $M, M E T H$ treated. Data are presented as mean \pm SEM; $n=5-6$ per group. Letters above the bars indicate significant effects $(p<0.05)$ of genotype $(\mathrm{g})$, treatment $(\mathrm{t})$, and/or genotype-treatment interaction (i) by a two-way analysis of variance (ANOVA) with the intersubject factors of genotype and treatment.

were quantified and analyzed by a two-way ANOVA with the intersubject factors of genotype and treatment (Figure 7c). Significant effects of treatment were found in the frontoparietal cortex $\left(\mathrm{F}_{1,18}=66.46, p<0.001\right)$, striatum $\left(\mathrm{F}_{1,18}=34.75, p<0.001\right)$, and piriform cortex $\left(\mathrm{F}_{1,18}=12.40\right.$, $p=0.002)$. We detected significant METH-induced IgG extravasation in the striatum, frontoparietal cortex, and in the piriform cortex of both $\operatorname{Fos} B(+/+)$ and $(-/-)$ mice (Figure $7 \mathrm{a}$ and $\mathrm{b}$ ), indicative of a particularly vulnerable $\mathrm{BBB}$ in these brain regions. It is notable that these brain areas are the same areas that exhibited FJB-positive cells (Figure 1). Especially, in the parietal cortex, IgG extravasation and FJB-positive neurons were confined to both layer III and superficial layer IV in the somatosensory cortex, area 1. Significant effects of genotype were found in the frontoparietal cortex $\left(\mathrm{F}_{1,18}=20.25, p=0.001\right)$ and in the piriform cortex $\left(\mathrm{F}_{1,18}=6.27, p=0.021\right)$, but not in the striatum $\left(\mathrm{F}_{1,18}=1.43, \quad p=0.246\right)$. Significant genotypetreatment interactions were found in the frontoparietal cortex $\left(\mathrm{F}_{1,18}=19.19, p<0.001\right)$ and piriform cortex $\left(\mathrm{F}_{1,18}=\right.$ $6.86, p=0.016)$, but not in the striatum $\left(\mathrm{F}_{1,18}=1.60\right.$, $p=0.220$ ). That is, after METH treatment, the frontoparietal and piriform cortices of $\operatorname{Fos} B(-/-)$ mice contained significantly more IgG-immunoreactive bodies than those of their $(+/+)$ littermates.

\section{DISCUSSION}

\section{Role of Fos Family Genes in Neuroprotection Against METH}

Methamphetamine neurotoxicity produces two major end results: monoaminergic terminal degeneration and postsynaptic, non-monoaminergic neuronal death. The latter can be due to apoptosis or necrosis (Gold et al, 2009). In this study, we showed that Fos $B(-/-)$ mice are more vulnerable to a neurotoxic regimen of METH administration by showing an increased FJB-positive degenerated neurons in the frontoparietal cortex and striatum. We found no evidence of exaggerated monoaminergic terminal degeneration (using tyrosine hydroxylase immunoreactivity or tissue monoamine contents) or of apoptosis (using TUNEL and caspase-3 staining) in METH-treated FosB $(-/-)$ brains compared with their $(+/+)$ littermates. Thus, our data suggest that FosB is more important for neuroprotection against nonapoptotic cell death in postsynaptic neurons, at least in the frontoparietal cortex and striatum. These findings contrast with c-Fos $(-/-)$ and $(+/-)$ mice, which show exacerbated striatal dopaminergic terminal loss and dopamine-reuptake sites, and more neuronal apoptosis in their cortices and striata (Deng et al, 1999). Thus, although both c-Fos and FosB are neuroprotective against METH-induced toxicity, their mechanisms of action appear to be distinct.

\section{Mechanisms of FosB-Mediated Protection of Postsynaptic Neurons}

Multiple mechanisms, including hyperthermia, mitochondrial stress and subsequent apoptosis, and BBB dysfunction, have been implicated in METH-induced neuronal death (Krasnova and Cadet, 2009). Among these, we attempted to dissect the relevant mechanisms by which FosB modulates responses to METH. We found that METH-induced hyperthermia was not exacerbated in Fos $B(-/-)$ mice. In contrast, we found that $\mathrm{BBB}$ dysfunction, visualized by $\operatorname{IgG}$ extravasation, was intensified in the cortices of Fos $B(-I-)$ mice. Moreover, the localities of IgG immunoreactive bodies were highly coincident with FJB-positive degenerating neurons, especially in the parietal cortex. Specifically, both FJB-positive cells and IgG-immunoreactive bodies were restricted to deep layer III and superficial layer IV of the parietal cortex, area 1. In addition, in the striatum of adjacent serial sections from the same mice, the distribution patterns of degenerating neurons and IgG immunoreactive bodies were very similar. These patterns, however, were not consistent with the ablation pattern of tyrosine hydroxylase immunoreactivity (data not shown). A previous report shows that the striatal subregion that contains the greatest 
a

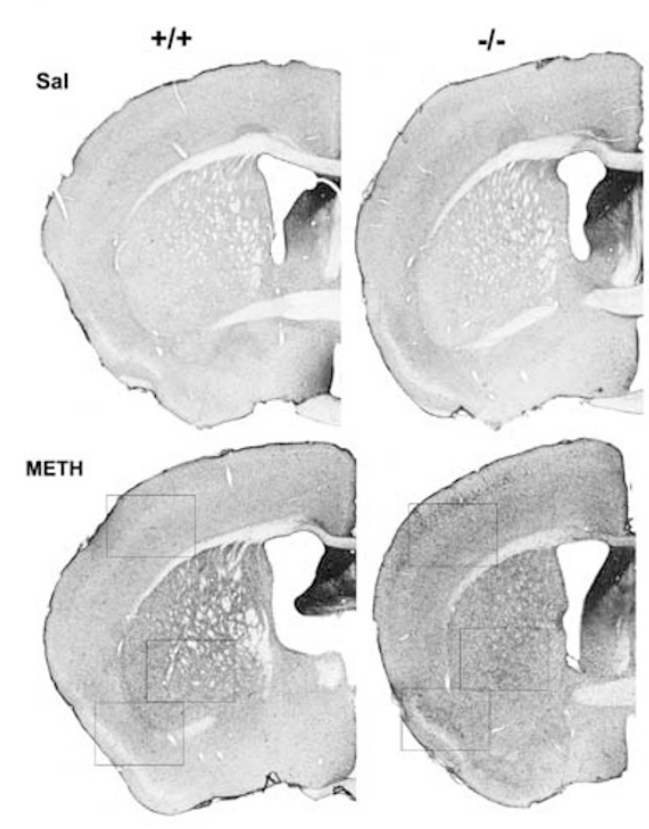

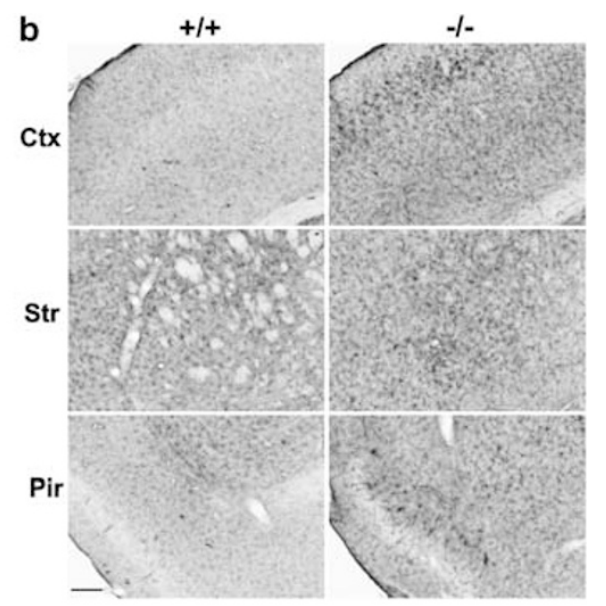

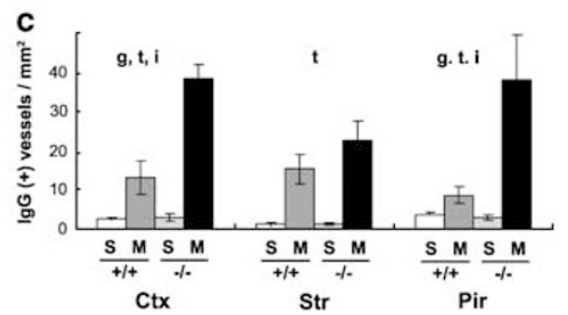

Figure 7 Effects of the FosB mutation on $\lg G$ extravasation after neurotoxic methamphetamine $(M E T H)$ administration. Fos $B(+/+)$ and $(-/-)$ mice were treated with four injections of saline $(S, n=5$ each) or $10 \mathrm{mg} / \mathrm{kg} \mathrm{METH}(\mathrm{M}, n=6$ each), and were examined for lgG leakage through the blood-brain barrier 3 days later by lgG immunostaining (a). (b) High magnification images of the rectangular fields illustrated in (a), from top to bottom, the frontoparietal cortex (Ctx), striatum (Str), and the piriform cortex (Pir) of METH-treated FosB $(+/+)$ and $(-/-)$ mice, respectively. Scale bar $=200 \mu \mathrm{m}$. (c) Mean \pm SEM counts of $\lg \mathrm{G}$ immunoreactive bodies. Letters above the bars indicate significant effects $(p<0.05)$ of genotype $(\mathrm{g})$, treatment $(\mathrm{t})$, and/or genotype-treatment interaction (i) by a two-way analysis of variance (ANOVA) with the intersubject factors of genotype and treatment.

numbers of degenerated neurons and axons is different from the subregion showing the greatest loss of tyrosine hydroxylase immunoreactivity (Bowyer et al, 2008). These findings suggest that the mechanism of dopamine terminal damage is distinct from the mechanism mediating postsynaptic neuronal death within the striatum. Of note, independent mechanisms of striatal dopamine terminal damage from that of parietal cortical cell injury have been reported. That is, animals pretreated with a dopamine transport inhibitor before METH show parietal cortical cell body injury; however, they do not show loss in striatal tyrosine hydroxylase immunoreactivity (Eisch et al, 1998). In this study, we found that the genetic inactivation of Fos $B$ causes the opposite effects from pharmacological inhibition of the dopamine transporter, ie, it does not enhance the loss of tyrosine hydroxylase immunoreactivity, but enhances parietal cortical cell injuries. FosB, therefore, might not be critically involved in the dopamine transporter-mediated METH action on dopaminergic terminals.

\section{FosB, Amino-Acid Metabolism, and Astroglial Function}

We found a decrease and/or attenuated induction of the small neutral amino acids, serine, alanine, and glycine after METH treatment in most of the Fos $B(-l-)$ forebrain areas analyzed. Although the amino-acid measurements in this study were not designed to distinguish the two stereoisomers of $\mathrm{L}$ - and $\mathrm{D}$-amino acids, most of the serine detected in this study is presumably the L-stereoisomer, as this constitutes the majority found in higher animals (Furuya and Watanabe, 2003). L-Serine is an important precursor of
D-serine. D-Serine and glycine are both potent co-agonists for NMDA-type glutamate receptors (Mothet et al, 2000). Moreover, L-serine and L-alanine themselves exert their effect as neurotrophic compounds, as they support the survival of neurons under serum- and glia-free culture conditions (Furuya et al, 2000). Altered regulation of these small amino acids in the forebrains of Fos $B(-/-)$ mice may therefore partly mediate the increased vulnerability of postsynaptic neurons after a neurotoxic dose of METH. This finding may also be relevant to the previous reports showing that $\operatorname{Fos} B(-/-)$ mice have decreased tolerance to repeated electroconvulsive seizures and reduced NMDA receptor upregulation in the superficial layers of the neocortex (Hiroi et al, 1998). Specific investigation of D-serine content and NMDA receptor function in FosB $(-/-)$ mutant mice could be an intriguing avenue for future studies.

L-Serine is produced mainly in astrocytes rather than in neurons (Furuya and Watanabe, 2003; Verleysdonk and Hamprecht, 2000). Thus, astroglial dysfunction is likely the cause of lower serine levels in the forebrain regions of Fos $B(-I-)$ mice. This notion is supported by our previous finding that astrocytes in the forebrains of $\operatorname{Fos} B(-I-)$ mice exhibited persistent upregulation of glial fibrillary acidic protein under basal conditions (Kuroda et al, 2008). Relevant to this topic, we found here that $\operatorname{Fos} B(-1-)$ frontoparietal and piriform cortices show enhanced METHinduced $\mathrm{BBB}$ dysfunction. Astrocytes, whose endfeet encircle neural capillaries, form the $\mathrm{BBB}$ together with vascular endothelial cells (Dietrich, 2009). As we found that neuronal death was colocalized with BBB dysfunction, 
astroglial dysfunction may mediate the enhanced METH toxicity in the forebrains of Fos $B(-/-)$ mice. Indeed, several studies have reported the relevance of $\mathrm{BBB}$ dysfunction with neuronal death (Bowyer and Ali, 2006a; Kiyatkin et al, 2007). In the case of the excitotoxic injury model made by hippocampal kinate injection, however, neuronal death and BBB breakdown are separate, independent processes: $B B B$ dysfunction occurs too late to initiate neurodegeneration, and $\mathrm{BBB}$ breakdown occurs without neuronal death (Chen et al, 1999). The causal relationship of these multiple events remains to be clarified.

Another puzzling fact is that FosB expression is confined primarily in neurons, as FosB expression in glial cells tends to be undetectable, even under stimulation (Herdegen and Leah, 1998). The FosB protein in neurons may therefore cause wide arrays of abnormalities in astrocyte metabolism through neuron-glia communication. Fos $B(-/-)$ mice might be an interesting model system for understanding the cross talk between neurons and glia cells.

\section{FosB-Mediated Intracellular Signaling Regulation in Response to Neurotoxic Doses of METH}

After psychostimulant administration, elevation of intracellular calcium levels and ERK phosphorylation occurs in many brain areas, resulting in the induction of Fos family transcription factors (Hope et al, 1994; Valjent et al, 2004). Our previous study shows that the null mutation of Fos $B$ attenuates upregulation of $S P R Y 1$ and $R A D$, negative feedback regulators of ERK and calcium signaling, respectively, in the medial preoptic area (Kuroda et al, 2007). Here we found that basal and stimulated expression of Sprouty and $R G K$ genes tended to be lower in FosB $(-/-)$ mice, with the only exception of higher GEM expression in the striatum of $\operatorname{Fos} B(-/-)$ mice. As mentioned in the Introduction, METH-induced GEM upregulation is dependent on c-Fos (Cadet et al, 2002). Therefore GEM induction could be overly compensated by c-Fos in the striatum of $\operatorname{Fos} B(-/-)$ mice. Sprouty is a major class of ligand-inducible inhibitors of RTK/ERK signaling pathway (Mason et al, 2006), and RGK is a potent inhibitor of calcium overinflux into activated cells (Kelly, 2005). Reduced expression of Sprouty and RGK can cause the overactivation of neurons, in terms of ERK phosphorylation and intracellular calcium elevation, respectively. Of note, it has been reported that the L-type calcium channel agonist BayK8644 can cause self-injurious biting (Jinnah et al, 1999). RGK proteins are known to downregulate calcium influx by sequestering L-type calcium channels (Kelly, 2005). These observations by no means prove our hypothesis that the ERK/calcium-Fos-Sprouty/ RGK molecular cascade could exert its effect as a negative feedback loop against METH-induced neurotoxicity, but at least are in accord. Fos target genes involved in such a general negative feedback might be found more easily than Fos target genes that have more specific functions in certain neuronal types. Indeed, all previous studies that have detected attenuated RGK induction in Fos-gene-targeted mice (Cadet et al, 2002; Kuroda et al, 2007; Salzmann et al, 2006) used grossly dissected brain tissue, containing different neuronal populations.

In summary, the current study suggests two possible mechanisms of FosB-mediated neuroprotection: one is through induction of negative feedback regulation within postsynaptic neurons through Sprouty and RGK. Another is supporting astroglial function such as maintenance of the $\mathrm{BBB}$, and metabolism of serine and glycine, which are important glial modulators of nerve cells. These two mechanisms are not necessarily mutually exclusive, and the former may cause the latter through the neuron-glia interaction. It is important to recognize, however, that ultimately the diverse findings provided here are correlative, and more directed study is necessary to provide a causative relationship.

\section{ACKNOWLEDGEMENTS}

We thank Yoshio Hirabayashi for helpful discussion, Tetsuaki Ara and Taeko Nemoto for technical assistance, and the RIKEN Research Resource Center for maintenance of animals. This research was supported by RIKEN, Grantsin-Aid for Scientific Research from the Ministry of Education, Culture, Sports, Science, and Technology, Japan (2006-2008 to KOK and KT) and by the Uehara Memorial Foundation (2009 to KOK).

\section{DISCLOSURE}

The authors declare no conflict of interest.

\section{REFERENCES}

Berghorn KA, Bonnett JH, Hoffman GE (1994). cFos immunoreactivity is enhanced with biotin amplification. J Histochem Cytochem 42: 1635-1642.

Bowyer JF (1995). The role of hyperthermia in amphetamine's interactions with NMDA receptors, nitric oxide, and age to produce neurotoxicity. Ann NY Acad Sci 765: 309-310.

Bowyer JF, Ali S (2006a). High doses of methamphetamine that cause disruption of the blood-brain barrier in limbic regions produce extensive neuronal degeneration in mouse hippocampus. Synapse 60: 521-532.

Bowyer JF, Robinson B, Ali S, Schmued LC (2008). Neurotoxicrelated changes in tyrosine hydroxylase, microglia, myelin, and the blood-brain barrier in the caudate-putamen from acute methamphetamine exposure. Synapse 62: 193-204.

Bowyer JF, Schmued LC (2006b). Fluoro-Ruby labeling prior to an amphetamine neurotoxic insult shows a definitive massive loss of dopaminergic terminals and axons in the caudate-putamen. Brain Res 1075: 236-239.

Brown JR, Ye H, Bronson RT, Dikkes P, Greenberg ME (1996). A defect in nurturing in mice lacking the immediate early gene fosB. Cell 86: 297-309.

Cadet JL, Jayanthi S, Deng X (2003). Speed kills: cellular and molecular bases of methamphetamine-induced nerve terminal degeneration and neuronal apoptosis. FASEB J 17: 1775-1788.

Cadet JL, McCoy MT, Ladenheim B (2002). Distinct gene expression signatures in the striata of wild-type and heterozygous c-fos knockout mice following methamphetamine administration: evidence from cDNA array analyses. Synapse 44: 211-226.

Chen ZL, Indyk JA, Bugge TH, Kombrinck KW, Degen JL, Strickland S (1999). Neuronal death and blood-brain barrier breakdown after excitotoxic injury are independent processes. J Neurosci 19: 9813-9820.

Curran-Everett D (2000). Multiple comparisons: philosophies and illustrations. Am J Physiol Regul Integr Comp Physiol 279: R1-R8. 
Davidson C, Gow AJ, Lee TH, Ellinwood EH (2001). Methamphetamine neurotoxicity: necrotic and apoptotic mechanisms and relevance to human abuse and treatment. Brain Res Brain Res Rev 36: 1-22.

Deng X, Ladenheim B, Tsao LI, Cadet JL (1999). Null mutation of c-fos causes exacerbation of methamphetamine-induced neurotoxicity. J Neurosci 19: 10107-10115.

Deng X, Wang Y, Chou J, Cadet JL (2001). Methamphetamine causes widespread apoptosis in the mouse brain: evidence from using an improved TUNEL histochemical method. Brain Res Mol Brain Res 93: 64-69.

Dietrich JB (2009). Alteration of blood-brain barrier function by methamphetamine and cocaine. Cell Tissue Res 336: 385-392.

Eisch AJ, Schmued LC, Marshall JF (1998). Characterizing cortical neuron injury with Fluoro-Jade labeling after a neurotoxic regimen of methamphetamine. Synapse 30: 329-333.

Franklin KBJ, Paxinos G (2007). The Mouse Brain in Stereotaxic Coordinates 3rd edn. Academic Press: San Diego. pp 360.

Furuya S, Tabata T, Mitoma J, Yamada K, Yamasaki M, Makino A et al (2000). -Serine and glycine serve as major astroglia-derived trophic factors for cerebellar Purkinje neurons. Proc Natl Acad Sci USA 97: 11528-11533.

Furuya S, Watanabe M (2003). Novel neuroglial and glioglial relationships mediated by L-serine metabolism. Arch Histol Cytol 66: 109-121.

Glowinski J, Iversen LL (1966). Regional studies of catecholamines in the rat brain. I. The disposition of $[3 \mathrm{H}]$ norepinephrine, $[3 \mathrm{H}]$ dopamine and $[3 \mathrm{H}]$ dopa in various regions of the brain. J Neurochem 13: 655-669.

Gold MS, Kobeissy FH, Wang KK, Merlo LJ, Bruijnzeel AW, Krasnova IN et al (2009). Methamphetamine- and traumainduced brain injuries: comparative cellular and molecular neurobiological substrates. Biol Psychiatry 66: 118-127.

Gown AM, Willingham MC (2002). Improved detection of apoptotic cells in archival paraffin sections: immunohistochemistry using antibodies to cleaved caspase 3. J Histochem Cytochem 50: 449-454.

Graybiel AM, Moratalla R, Robertson HA (1990). Amphetamine and cocaine induce drug-specific activation of the $c$-fos gene in striosome-matrix compartments and limbic subdivisions of the striatum. Proc Natl Acad Sci USA 87: 6912-6916.

Herdegen T, Leah JD (1998). Inducible and constitutive transcription factors in the mammalian nervous system: control of gene expression by Jun, Fos and Krox, and CREB/ATF proteins. Brain Res Brain Res Rev 28: 370-490.

Hiroi N, Brown JR, Haile CN, Ye H, Greenberg ME, Nestler EJ (1997). FosB mutant mice: loss of chronic cocaine induction of Fos-related proteins and heightened sensitivity to cocaine's psychomotor and rewarding effects. Proc Natl Acad Sci USA 94: 10397-10402.

Hiroi N, Marek GJ, Brown JR, Ye H, Saudou F, Vaidya VA et al (1998). Essential role of the FosB gene in molecular, cellular, and behavioral actions of chronic electroconvulsive seizures. J Neurosci 18: 6952-6962.

Hope BT, Nye HE, Kelz MB, Self DW, Iadarola MJ, Nakabeppu Y et al (1994). Induction of a long-lasting AP-1 complex composed of altered Fos-like proteins in brain by chronic cocaine and other chronic treatments. Neuron 13: 1235-1244.

Jinnah HA, Yitta S, Drew T, Kim BS, Visser JE, Rothstein JD (1999). Calcium channel activation and self-biting in mice. Proc Natl Acad Sci USA 96: 15228-15232.

Katayama K, Yamada K, Ornthanalai VG, Inoue T, Ota M, Murphy NP et al (2008). Slitrk1-deficient mice display elevated anxietylike behavior and noradrenergic abnormalities. Mol Psychiatry (E-pub ahead of print).

Kelly K (2005). The RGK family: a regulatory tail of small GTPbinding proteins. Trends Cell Biol 15: 640-643.

Kita T, Wagner GC, Nakashima T (2003). Current research on methamphetamine-induced neurotoxicity: animal models of monoamine disruption. J Pharmacol Sci 92: 178-195.
Kiyatkin EA, Brown PL, Sharma HS (2007). Brain edema and breakdown of the blood-brain barrier during methamphetamine intoxication: critical role of brain hyperthermia. Eur J Neurosci 26: $1242-1253$.

Krasnova IN, Cadet JL (2009). Methamphetamine toxicity and messengers of death. Brain Res Rev 60: 379-407.

Kuroda KO, Meaney MJ, Uetani N, Fortin Y, Ponton A, Kato T (2007). ERK-FosB signaling in dorsal MPOA neurons plays a major role in the initiation of parental behavior in mice. Mol Cel Neurosci 36: 121-131.

Kuroda KO, Meaney MJ, Uetani N, Kato T (2008). Neurobehavioral basis of the impaired nurturing in mice lacking the immediate early gene FosB. Brain Res 1211: 57-71.

Le Foll B, Diaz J, Sokoloff P (2005). A single cocaine exposure increases BDNF and D3 receptor expression: implications for drug-conditioning. NeuroReport 16: 175-178.

Mason JM, Morrison DJ, Basson MA, Licht JD (2006). Sprouty proteins: multifaceted negative-feedback regulators of receptor tyrosine kinase signaling. Trends Cell Biol 16: 45-54.

McCann UD, Ricaurte GA (2004). Amphetamine neurotoxicity: accomplishments and remaining challenges. Neurosci Biobehav Rev 27: 821-826.

Mothet JP, Parent AT, Wolosker H, Brady Jr RO, Linden DJ, Ferris $\mathrm{CD}$ et al (2000). -Serine is an endogenous ligand for the glycine site of the N-methyl-D-aspartate receptor. Proc Natl Acad Sci USA 97: 4926-4931.

Nestler EJ (2001). Molecular basis of long-term plasticity underlying addiction. Nat Rev Neurosci 2: 119-128.

Numan M, Numan MJ, Marzella SR, Palumbo A (1998). Expression of c-fos, fos B, and egr-1 in the medial preoptic area and bed nucleus of the stria terminalis during maternal behavior in rats. Brain Res 792: 348-352.

Perneger TV (1998). What's wrong with Bonferroni adjustments. BMJ 316: $1236-1238$.

Ryan LJ, Linder JC, Martone ME, Groves PM (1990). Histological and ultrastructural evidence that $\mathrm{D}$-amphetamine causes degeneration in neostriatum and frontal cortex of rats. Brain Res 518: 67-77.

Sakurai S, Ishii S, Umino A, Shimazu D, Yamamoto N, Nishikawa T (2004). Effects of psychotomimetic and antipsychotic agents on neocortical and striatal concentrations of various amino acids in the rat. J Neurochem 90: 1378-1388.

Salzmann J, Canestrelli C, Noble F, Marie-Claire C (2006). Analysis of transcriptional responses in the mouse dorsal striatum following acute 3,4-methylenedioxymethamphetamine (ecstasy): identification of extracellular signal-regulated kinase-controlled genes. Neuroscience 137: 473-482.

Schmued LC, Bowyer JF (1997). Methamphetamine exposure can produce neuronal degeneration in mouse hippocampal remnants. Brain Res 759: 135-140.

Schmued LC, Hopkins KJ (2000). Fluoro-Jade B: a high affinity fluorescent marker for the localization of neuronal degeneration. Brain Res 874: 123-130.

Sulzer D, Sonders MS, Poulsen NW, Galli A (2005). Mechanisms of neurotransmitter release by amphetamines: a review. Prog Neurobiol 75: 406-433.

Tata DA, Yamamoto BK (2007). Interactions between methamphetamine and environmental stress: role of oxidative stress, glutamate and mitochondrial dysfunction. Addiction 102(Suppl 1): 49-60.

Valjent E, Pages C, Herve D, Girault JA, Caboche J (2004). Addictive and non-addictive drugs induce distinct and specific patterns of ERK activation in mouse brain. Eur J Neurosci 19: $1826-1836$

Verleysdonk S, Hamprecht B (2000). Synthesis and release of L-serine by rat astroglia-rich primary cultures. Glia 30: 19-26.

Wagner GC, Avena N, Kita T, Nakashima T, Fisher H, Halladay AK (2004). Risperidone reduction of amphetamine-induced selfinjurious behavior in mice. Neuropharmacology 46: 700-708. 